\title{
Errors in Compositions of The Students of SMKN 2 Tegallalang
}

\author{
I Wayan Diarsa ${ }^{1}$, Nyoman Sujaya ${ }^{2}$, Ni Made Suwendri ${ }^{3}$ \\ Universitas Warmadewa Denpasar-Bali, Indonesia ${ }^{1,2,3}$ \\ \{diarsa@gmail.com¹, madesuwendri@gmail.com ${ }^{3}$ \}
}

\begin{abstract}
This study aims to explore the grammatical errors made by the students of SMKN 2 Tegallalang in practicing English. The theory applied for this study is Error Analysis Perspectives on Second Language Acquisition (1974) edited by Jack C. Richards. In this study, the method applied is descriptive analysis method. The data of the analysis are taken from the compositions by the students of SMKN 2 Tegallalang. As a results of analysis show that some errors are made by the students in writing a sentence. Actually those students are able to use English in writing, but they still made some errors. The most error they committed like singular-plural, word form, word choice, verb tense, add word, omit word, word order, spelling, punctuation, an article, unclear idea, and error of run-on sentence. In conclusion, the students have learned English for some years in junior high school, but they still make many errors in practicing their English. Definitely, it's a big deal for English teacher and institution in improving those students skill. Also, found some factors that cause the students still made errors, such as age and motivation and lack of awareness of EFl.
\end{abstract}

Keywords: Error analysis; errors in compositions; second language acquisition

\section{Introduction}

Language is a significant piece of our life. It is utilized by human to speak with one another. We can likewise utilize the language to communicate our inclination or feeling. The language will likewise permit us to adjust to society. Language is a piece of human culture that can't be isolated from human life. Evaluations number of dialects on the planet different, and English is one of them. English is a worldwide language and it is utilized as global correspondence in term of business, legislative issues, culture, innovation, and other social exercises. In view of the significance of English in numerous nations, English is utilized as a subsequent language. As a result of this significance, in Indonesia, English is educated at certain degrees of school. English is instructed from pre-grade school until college level. It implies that English is offered at any degree of schools as one of the subjects they study. In Senior High School, English is even offered for a long time seven days.

The reality shows that despite the fact that they have examined English since they were in pre-grade school, the vast majority of them can't communicate in English. The issue in learning English is maybe brought about by the intricacy of English language. Probably, they don't learn 
English genuinely. The understudies need a great deal of training on the off chance that they need to have the option to communicate in English well. In view of the perception that had been done in SMKN 2 Tegallalang, numerous students of SMKN 2 Tegallalang were not sure with their English. They didn't know a lot of English language structures.

The following explanation are some latest research concerning to errors in English that made by student such as ${ }^{[1]}$ discovered that there are ten characterizations of mistake dependent on the mix of etymological class and surface methodology scientific categorization. They are To Be, action word, bound morpheme - s/ - es, jargon, thing, linguistic structure, relational word, article, combination and modifier. Additionally, discovered 2 predominant wellsprings of mistake, specifically interlingual move and intralingual transfer. Furthermore, the study ${ }^{[2]}$ revealed in his study that the blunders can be assembled into fifteen classifications going from extreme mistakes to mellow mistakes, they are word decision, action word gathering, article, relational word, majority and spelling. Different classes are subject-action word arrangement, pronoun understanding and dropping, relative condition, possessive, copula exclusion and specialist. In light of these discoveries, the educator of English is proposed to raise students' mindfulness on these mistakes and give adequate solutions for keep students from disguising such errors. In line with ${ }^{[3]}$ found the errors in the compositions are 30 items or $15 \%$ for errors of selection, 25 items or $12,5 \%$ for errors of ordering, 115 items or $57,5 \%$ for errors of omission and 30 items or $15 \%$ for errors of addition. Some identifying, classifying, analyzing and correcting the errors have been done to correct the errors that have been found. It was done in order to minimize and avoid the same errors happen again in the learners' English narrative composition. Based on the previous research, this present study also aims to analyse error in compositions made by the students of SMKN 2 Tegallang in practicing English. This study did in order to improve students' ability in mastering English as a foreign language.

\section{Methods}

This study was designed in descriptive qualitative method. The data of this study is taken from the students' compositions of SMKN 2 Tegallalang on 10th grade. In this case, the data is collected by giving a writing exercise to practice their English. The data are described and analyzed qualitatively. Then, the data analysis was presented in the form of narrative into paragraph.

\section{Results and Discussion}

\subsection{English Errors Found in the Compositions}

Error analysis is a strategy to distinguish, characterize and interpret systematically the unadaptable structures which is delivered when learning an unknown dialect utilized a few standards and systems gave by Linguistics. As mentioned before that there are 14 errors in English ${ }^{[4]}$. They are singular-plural, word form, verb tense, word choice, add word, omit word, word order, incomplete sentence, spelling, punctuation, capitalization, article, meaning not clear, and run-on sentence. All of them are found in the compositions of the students of SMKN 2 Tegallalang in the year of 2016/2017. All of the statuses are categorized into some English errors which can be seen as bellow: 


\section{a) The Error of Singular-Plural}

Commonly, plural noun is identified by added $s$ or es to the singular. From the data analysis found some sentences which have singular-plural error. The sentences provided as follows:

There are many kind of food. (D04)

I hope everything are good. (D12)

On the sentence (1) word "many" is an adjective that explains about a quantity and it absolutely means more than one thing. When word many are followed by a noun, that should be followed by a plural noun. The correct sentence should be "There are many kinds of food." On the sentence (2), it was also identified as a singular-plural error. The italic word is incorrect if the subject of the word is everything. The word everything is classified into a noun that refers to a singular noun and It should be followed by is. The correct sentence can be "I hope everything is good."

\section{b) The Error of Word Form}

Generally, the error of word form lies on the incorrect word. In this data found two sentences which is one of them have error as follows.

My mother is beauty short woman. (D05)

She is beautiful with around face. (D05)

On the sentence (1), the italic word in the sentence is showing word form error. Word beauty is a noun and it should be an adjective because it's describing the subject. The sentence should be written, "My mother is beautiful short woman." On sentence (2), the italic word around is a kind of adverb, and it should be in adjective form round that is describing the word face. The correct sentence should be "She is beautiful with round face."

\section{c) The Error of Verb Tense}

Verb tense error usually lies on selection of types of verbs that are not in accordance with the tenses in English. The error frequently occurred in writing a sentence. As a result of analysis, the following sentences show some verbs tense error. The sentences are taken from the data as examples of the verb error are presented below.

Last week, Agus and I will go to library. (D08)

We are a friend since 5 years ago. (D11)

On the sentence (1), the italic word will go is showing the verb tense error. It is should be past form went because the word last week is an adverbial that mention about past time. The correct sentence should be "Last week, Agus and I went to library." On the sentence (2), the italic word are is showing the verb tense error and it should be have been. The word since explains that the sentence is present perfect tense. The correct sentence should be "We have been a friend since 5 years ago."

\section{d) The Error of Word Choice}

It is not different in meaning, it just needs an appropriate time to use a word in a sentence. From the data of analysis, there are sentences that are recognized into word choice error, they are:

She hobby is singing. (D05)

He asked the money to buy food. (D08) 
On the sentence (1), the italic word she is a word choice error. It is incorrect to be written on that sentence because it needs possessive word form. It should be changed to be better word choice as "Her hobby is singing." On sentence (2), I found a word choice error, the italic word to buy in this sentence refers to a word choice error. It will be better if the writer choose the word for buying for replace it. The correct sentence should be "He asked the money for buying food."

\section{e) The error of Add Word}

It is a view word in a sentence and much less than common. In the data, it was found sentences that are categorized as types of add word error. They are presented below.

She likes to cooking. (D11)

I want to invite the visit you to come to my house. (D15)

On the sentence (1), there is a word that contains add word error. The word to must be omitted. Word cooking is in verb-ing form. So, it does not need the word to to separate the two verbs. The correct sentence can be "She likes cooking." On the sentence (2), the italic word indicates add words error, it should be omitted. The better sentence is "I want to invite you to come to my house."

\section{f) The Error of Omit Word}

The omit word error means some words were eliminated in the sentences. Frequently, it occurs in quoting or deleting one word within sentence. From the data of analysis, there are sentences that are recognized into omit word error, the sentences are:

He ... very handsome young man. (D01)

His body ... slender. (D06)

On sentence (1), the underlined word contains an omit word error that should be filled in the sentence. This could be fixed to add is due the subject on the sentence, is he. So, the correct sentence should be "He is very handsome young man." On sentence (2), the underlined word contains an omit word error that should be filled on the sentence. This could be fixed to add is due the subject is his body. So, the correct sentence should be "His body is slender."

\section{g) The Error of Word Order}

Adjective deals with amounts or quantities, normally precede the noun or pronoun to which they refer, even when the verb to be used. Based on the data, there are some sentences with word order errors are found. They are:

I felt proud very. (D04)

Michael Douglas is an American actor very famous and popular. (D06)

On the sentence (1), the sentence I felt proud very is showing word order error, for the better sentence we can change the sentences into "I felt very proud." On the sentence (2), sentence Michael Douglas is an American actor very famous and popular is showing word order error, for the better sentence we can change the sentences into "Michael Douglas is a very famous and popular American actor."

\section{h) The Error of Incomplete Sentence}


Incomplete sentence is the error which is identified by short sentence and meaningless. There are many aspects to determine a incomplete sentence. Based on the data analysis, some sentences with incomplete sentence errors are found, they are:

We never hope. (D04)

You can go with your friend. (D15)

On sentence (1) We never hope is showing incomplete sentence error. A good complete sentence is having subject, predicate and object. It will be correct if the writer adds the object. The sentence could be changed into "We never hope that our school became a winner." On sentence (2), the sentence is showing incomplete sentence error. It is recognized as an incomplete sentence error because there is not an adverbial place after the word go. The correct sentence could be "You can go to the party with your friend."

\section{i) The Error of Spelling}

Spelling error is a mistakes lies on unfamiliar syllable word that makes word is difficult to recognize and meaningless. Spelling is very significant in writing a word or sentence. The reality, sometimes this error happens to somebody. There are some mistakes in some sentences of the data analysis.

I really mis you. (D03)

Shi is funny woman. (D05)

The sentence (1) shows spelling error, the italic word mis in the sentence is incorrect. This is not good spelling. Then, the better sentence could be "I really miss you." The sentence (2) shows spelling error, the italic word shi in the sentence is incorrect. This is not good spelling. Then, the better sentence could be "She is funny woman."

\section{j) The Error of Punctuation}

The using of punctuation is very significant because it can make a different meaning in a sentence. There are almost all of the sentence should be consist of punctuation. In the data analysis there are some sentences which are an error in applying punctuation.

She' is strong and patient. (D05)

Hello, how are you. (D12)

Inn sentence (2) is categorized into punctuation error. This sentence uses apostrophe after the subject. So, the correct sentence could be "She is strong and patient." In sentence (3) is categorized into punctuation error because used a full stop at end of sentence. The sentence should be formed as follows: "Hello, how are you?"

\section{k) The Error of Capitalization}

Capitalization is the way of writing a word in which the first letter of word is uppercase and other remain in lowercase. In using capitalization, there are some criteria should be obeyed such as capitalizing in a certain term, name of countries, weeks, months, locations, brands, proper names, and so on. However, in this data found hardly every sentence have problems as shown us in the following sentences.

He is English teacher. (D01)

on the second day I returned to gianyar for taking the reward. (D04)

On sentence (1) the italic word english showing the capitalization error. The correct sentence could be "He is English teacher. On sentence (2), the italic word on and gianyar are 
showing the capitalization error. The sentence and name of place should be begin with capitalization. The correct sentence could be "On the second day I returned to Gianyar for taking the reward."

\section{1) The Error of Article}

This error is recognized by using a wrong determiner in a sentence. There are some rules in writing an article, such as using an article $a$ before words that begin with consonant sound and $a n$ is used before vocal sound. Based on the data there are 3 sentences that are error in applying article. They are:

That our school became an winner. (D04)

She looks like an person who is easy to talk to you. (D05)

On sentence (1), the italic article an is showing the article error. Article an is used before the vocal sound in begin of the word. So the correct sentence could be "That our school became a winner." On sentence (2), the italic article an is showing the article error. Article an is used before the vocal sound in begin of the word. So the correct sentence could be "She looks like a person who is easy to talk to you."

\section{m) The Error of Meaning Not Clear}

Usually, this error caused by a lack knowledge of English and they did not know how to express their feeling into a good sentence so that it caused an unclear meaning. From the data analysis, there are sentences that have this error. They are:

Because I am a lot. (D10)

She is very work. (D11)

On sentence (1) the sentence has unclear meaning. Perhaps, it shows that the subject having a lot of something. So, the better sentence could be "Because I have many friends." On sentence (2) the sentence has unclear meaning. Perhaps, it describes the subject that she is a hard worker woman. So, the better sentence could be "She is a very hard worker."

\section{n) The Error of Run-on Sentence}

Run-on sentence is a sentence in which two or more independent clauses are inaccurately combined by comma without using coordinator conjunction or sentence connector. This error is also called run-together sentence or coma splice. Based on the data, there are sentences with this error. They are:

Inna Sindhu Beach have the restaurant located at the beach for breakfast, lunch and dinner.

(D18)

He is smart teacher, I like when he is teaching. (D01)

In sentence (1) shows the run-on sentence error was written into two sentences. There are two points that explained by the sentence. First, explaining about location, and second something that offered. The better sentence could be "Inna Sindhu Beach has the restaurant located at the beach. The restaurant serves breakfast, lunch and dinner." In sentence (2) the sentence shows run-on sentence error because it should be written into two sentences and adding a period between it. The better sentence could be "He is smart teacher. I like when he is teaching." 


\subsection{The Factors of the Students Made Errors}

\section{a) Age}

Most of the students are 17 years old did not get a lot of experiences in learning and practicing their English. They are real students and just focuses on learning anything, so they do not have a lot of chance to practice their English with the foreigner. Moreover, the students did not use English at home too.

\section{b) Motivation}

English is very important in their major. They need to be able to speak English properly because they will serve the foreigner in hotel. On their seventeenth, most of them did not get a big motivation to learn English. The students still were not aware of the importance of English and still very lack of attention to English lesson.

\section{c) English as a Foreign Language}

In Indonesia particularly considered English as a foreign language so that English only being an additional lesson. Moreover, students of SMKN 2 Tegallalang just learn English at school and never practice it in social communication with friends or family.

\section{Conclusion}

In view of the investigation found that the types of errors comprises of a few classifications, they are Singular-plural, Word structure, Verb tense, Word decision, Add the word, Omit word, Word request, Incomplete sentence, Spelling, Punctuation, Capitalization, Article, Meaning is unclear, and Run-on sentence. It was discovered 42 syntactic blunders in the students' compositions. Most mistakes discovered are error of spelling. There are 5 sentences that are error of spelling. The low quantities of error discovered are error of run-on sentence and mistake of word structure. There are 2 sentences in each. The information are found in the entirety of the understudies' pieces. It implies the entirety of the students make error in rehearsing their English. The students have learned English for certain years in middle school, however they actually make numerous errors in rehearsing their English. It is enormous issue for the English educator and organization. There are a few factors that made the students made a few blunders, for example, their age, their inspiration, and English as an unknown dialect.

\section{References}

[1] R. Mufidah, "An Error Analysis of Composition Written by English Department Students of Muhammadiyah Universitas of Surakarta," 2011.

[2] H. Hamzah, "An Analysis of the Written Grammatical Errors Produced by Freshment Students in English Writing," Lingua Didaktika: Jurnal Bahasa dan Pembelajaran Bahasa, vol. 6, no. 1, p. 17, Dec. 2012.

[3] P. Kusumawardhani, "Error Analysis in Writing an English Narrative Composition," Lingua Cultura, vol. 9, no. 2, p. 132, 2015. 
[4] J. C. Richards, Error Analysis Perspective on second Language Acquisition. Singapore: Longman, 1974. 